Рисунок 3 - Прототип экранной формы.

Но следует уточнить, что внедряемая система уже сейчас позволяет структурировать поступающий поток заявок. Тем самым, значительно сокращая издержки системного администратора при планировании и отслеживании текущего фронта работ.

Таким образом, основным способом оптимизации деятельности по поддержки работы пользователей в сети предприятия является создание многоуровневой системы обработки поступающих заявок, способной свести к минимуму организационные проблемы и эффективно распределять нагрузку между сотрудниками службы технической поддержки.

$$
* * *
$$

1. Обязанности Службы Service Desk, eе функции, уровни кадрового обеспечения и проч. [Электронный pecypc]. - Режим доступа: https://project.dovidnyk.info/index.php/itil/podderzhkauslug/396obyazannosti_sluzhby_service_desk_ee_funkcii_urovni_kadrovogo_obespecheniya_i_proch__ (дата обращения: 17.03 .2018 )

2. Управление инцидентами и проблемами [Электронный ресурс]. - Режим доступа: https://www.osp.ru/os/2001/07-08/180310/ (дата обращения: 17.03.2018)

3. HelpDesk и ServiceDesk. Что это и зачем это нужно вашей компании [Электронный ресурс]. - Режим доступа: https://habrahabr.ru/company/deskun/blog/331354/ (дата обращения: 17.03.2018)

4. Разработка проекта по внедрению системы Redmine в деятельность отдела программирования [Электронный ресурс]. - Режим доступа: https://www.scienceforum.ru/2015/890/8218/ (дата обращения: 17.03.2018)

5. Help Desk (helpdesk) или Service Desk [Электронный pecypc]. - Режим доступа: http://www.inframanager.ru/itsapiens/articles/helpdesk/ (дата обращения: 17.03.2017)

\title{
Шивкова Е.Г. \\ Повышение производительности тестирования программного обеспечения при управлении тестовыми данными
}

Российский университет транспорта (РУТ (МИИТ)) (Россия, Москва)

doi:10.18411/lj-31-03-2018-18

idsp: 000001:lj-31-03-2018-18

Аннотация

Управление тестовыми данными помогает организациям создавать более качественное программное обеспечение, которое будет надежно работать при развертывании. Он предотвращает исправления ошибок и откаты и в целом создает более экономичный процесс развертывания программного обеспечения. Это также снижает риски организации и риски безопасности.

Ключевые слова: тестирование, программное обеспечение, производительность, управление тестовыми данными.

\section{Зачем рассматривать управление тестовыми данными?}

Управление тестовыми данными подразумевает планирование, проектирование, хранение и управление процессами и методологиями тестирования программного обеспечения. Это позволяет командам качества программного обеспечения и тестирования контролировать и проверять данные, файлы, методологии и политики на протяжении всего жизненного цикла тестирования программного обеспечения.

Основная цель - создавать, управлять и поддерживать исходные коды приложения или программного обеспечения для тестирования. Благодаря управлению тестовыми данными возможно отделить тестовые данные от производственных данных и сохранить версию тестируемого программного обеспечения, отслеживание ошибок и другие процессы тестирования программного обеспечения. 
Другой ключевой задачей управления тестовыми данными является минимизация и оптимизация объема данных тестирования программного обеспечения и в то же время сопоставление, централизация и стандартизация документации по тестированию программного обеспечения и ресурсов тестирования. Это важно во время жизненного цикла тестирования, когда данные, сгенерированные и сопоставленные, массивны для тестирования приложения или программного обеспечения. Когда результаты сообщаются, это сокращает время, затрачиваемое на обработку данных. Это также помогает повысить эффективность общего приложения или программного обеспечения.

Необходимо учитывать следующий контрольный список во время управления тестовыми данными:

- Общие элементы данных;

- Архивирование и сохранение данных;

- Организация и распределение тестовых данных;

- Создание отчетности и мониторинга;

- Приоритет в распределении тестовых данных;

- Разработка автоматизации тестирования для подготовки основных данных;

- Ведение версий тестовых данных, процессов и стандартов.

Каким образом можно повысить производительность анализа данных?

С традиционными процессами разработки программного обеспечения команды разработчиков обычно имеют неадекватный доступ к тестовым данным. Это в первую очередь приводит к необходимости эффективного управления тестовыми данными. Он может расширить возможности групп разработчиков и подниматься выше проблем с данными.

Минимальный порог разрабатываемых и тестируемых приложений резко возрастает. В результате команды тестирования и разработки не смогут работать отдельно друг от друга. Им нужен полный доступ к методологиям тестирования, результатам выполнения тестов и стандартам. Это помогает внедрять усовершенствования и исправления на каждом уровне и создавать условия для разработки при непрерывном тестировании.

Организации соблюдают преимущества управления тестовыми данными и даже конфиденциальность для управления производственными данными. Методологии разработки и тестирования нового поколения требуют более быстрых и более повторяющихся циклов выпуска для решения различных новых задач, поставленных цифровым миром. В этом контексте организациям становится неизбежным создание тестовой среды и необходимыми тестовыми данными и стандартами тестирования. Автоматизация тестирования может помочь ускорить этот процесс в конвейере доставки программного обеспечения, где каждый элемент становится автоматическим, и процесс остается итеративным. Это не позволяет прерывать проект из-за ограничений скорости или задержки обнаружения ошибок.

Отслеживание ошибок имеет решающее значение и может стоит огромных денег для предприятия. Управление тестовыми данными помогает обеспечить правильные тестовые данные в нужное время для необходимых действий. Одной из основных причин отказа приложения является неадекватность тестовых данных с командами разработчиков.

\section{Задачи и рекомендации по управлению тестовыми данными}

Количество инструментов управления тестовыми данными на рынке продолжает расти в соответствии с такими инструментами, как инструмент архивирования данных, инструменты ETL, аппаратные средства хранения на дисках и т.д. Тем не менее, разрыв преобладает, и становится необходимым понять основные проблемы с управлением тестовыми данными. 
Одной из ярких проблем является сохранение безопасности данных. Если были случаи сбоев данных, то это может повлиять на процесс разработки приложений и сами данные. Помимо этого, быстрый рост объема тестовых данных и связанные с ними конечные затраты постоянно растут. Организации работают над улучшением повторного использования данных. Опытные команды управления тестовыми данных пытаются использовать новые технологии, чтобы сделать требуемые данные доступными с легкостью, безопасностью и скоростью. Виртуализация данных рассматривается как решение, где виртуальные данные могут быть доступны в течение нескольких минут и не несут физических затрат на инфраструктуру. Чтобы продолжать непрерывное тестирование, виртуализация данных дополнительно оснащает конечных пользователей элементами управления данными самообслуживания для исходных данных в любое время в любом месте. Это помогает сделать процесс тестирования программного обеспечения более итеративным и сократить задержку. Развитые и опытные ИТ-организации идут дальше с управлением тестовыми данными, в частности, с интегрированной маскировкой и распределением данных. При этом администраторы могут предоставить практически доступные данные командам разработчиков в течение нескольких минут и даже запустить алгоритм повторного маскирования для согласования процессов разработки и транзакций.

В целом эффективное управление тестовыми данными тестирования облегчает быструю доставку приложений, снижает затраты и, следовательно, улучшает согласованность с бизнес-моделями.

$$
* * *
$$

1. Хамбл Дж., Фарли Д. Непрерывное развертывание ПО: автоматизация процессов сборки, тестирования и внедрения новых версий программ, Управление данными, с. 317-332 